\title{
AVALIAÇÃO DAS PROPRIEDADES MECÂNICAS DE ARGAMASSA PARA ENCUNHAMENTO PARA MINIMIZAÇÃO DAS MANIFESTAÇÕES PATOLÓGICAS EM SVVIE
}

\author{
DE LORENZI FONSECA DE OLIVEIRA, JOSIELE \\ Arquiteta e urbanista, Pós graduação em \\ Patologia das Construções \\ UNISINOS - Univ. do Vale do Rio dos Sinos \\ Rio Grande do Sul; Brasil \\ josidelorenzi@ terra.com.br
}

\section{CHRIST, ROBERTO}

Pós graduação - Doutorado em Engenharia Civil ittPerformance UNISINOS- Univ.Vale do Rio dos Sinos

Rio Grande do Sul; Brasil

rchrist@unisinos.br
FRIEDERICH DOS SANTOS, MARCUS DANIEL

Mestre em Engenharia Civil

UNISINOS - Univ. doVale do Rio dos Sinos

Rio Grande do Sul; Brasil

marcus@mmcprojetos.com.br

\section{PACHECO, FERNANDA}

Pós graduação - Doutorado em Engenharia Civil

ittPerformance UNISINOS-Univ.Vale do Rio dos Sinos

Rio Grande do Sul; Brasil

fernandapache@unisinos.br

\section{RESUMO}

Surgiram várias manifestações patológicas especialmente na zona de encunhamento, necessita-se de uma norma brasileira específica de execução e parâmetros das argamassas para encunhamento. O objetivo deste trabalho foi avaliar as propriedades mecânicas de resistência à compressão e à tração e o módulo de elasticidade, das argamassas. Iniciou-se uma análise comparativa entre os profissionais da área. Catalogaram-se dados de características físicas, modo de execução e preparo de 7 empresas de argamassas industrializadas e 3 aditivos expansor, foram produzidas 2 industrializadas e 2 com traço areia:cimento:aditivo, de marcas e volumes diferentes. Moldou-se 3 corpos de prova 4x4x16cm, para cada traço, conforme NBR13279. Os resultados das propriedades mecânicas das argamassas não foram satisfatórios. Apenas uma entre as argamassas ensaiadas, sendo utilizada na função de encunhamento, com baixa resistência mecânica de flexão e compressão, influenciando no resultado do módulo de elasticidade.

Palavras-chave: argamassa, encunhamento, módulo de elasticidade, resistência compressão, resistência à flexão.

\section{ABSTRACT}

Several pathological manifestations have arisen especially in the wedge zone. Thus, a specific Brazilian standard of execution and parameters of wedge mortars is required. The objective of this work was to evaluate the mechanical properties of compressive and tensile strength and the modulus of elasticity of mortars. A comparative analysis was started among professionals in the area. Physical characteristics, execution and preparation data of 7 industrialized mortar companies and 3 expander additives were cataloged, 2 industrialized and 2 sand-traced: cement: additive, of different brands and volumes. Three $4 \times 4 \times 16 \mathrm{~cm}$ specimens were molded for each trait, according to NBR13279. The results of the mechanical properties of mortars were not satisfactory. Only one among the mortars tested, being used in the wedging function, with low mechanical resistance of flexion and compression, influencing the result of the modulus of elasticity.

Keywords: mortar, wedging, modulus of elasticity, compressive strength, flexural strength.

\section{INTRODUÇÃO}

Houve uma grande mudança na maneira de construir no Brasil nos últimos anos, edifícios mais altos e esbeltos, com grandes vãos e redução de pilares, as deformações imediatas e lentas da estrutura que, se não previstas, podem ser uma das causas das manifestações patológicas na ligação entre a estrutura e a última fiada da alvenaria de vedação (CAPORRINO, 2018; DALDON, 2008; THOMAZ, 2007)

Qualquer sistema se deforma, o importante é o grau de flexibilidade dos componentes (vigas e lajes) (THOMAZ, 2007) e como ela se comporta para definição do sistema de fixação e/ou a argamassa de encunhamento a ser utilizada. Cabe destacar que a NBR 8545:84 não leva em consideração este requisito e não classifica o tipo de encunhamento a ser utilizado, tampouco tem-se isso em outras normas (CAPORRINO, 2018; DALDON, 2008; THOMAZ, 2007). 
Infelizmente há pouca bibliografia sobre o assunto, muitas divergências dos materiais a serem utilizados. Assim, este artigo visou contribuir com dados coletados em testes laboratoriais de ensaios de módulo de elasticidade, resistência à compressão e flexão na tração, resultados obtidos das amostras das argamassas industrializadas para encunhamento e argamassas com aditivos expansor. Os parâmetros foram comparados e concluídos em dados estatísticos, além de agregar para pesquisas futuras e técnicas de execução, até a viabilização de normas brasileiras específicas para execução e parâmetros para argamassa de encunhamento.

\section{FUNDAMENTAÇÃO TEÓRICA}

A ocorrência de várias manifestações patológicas na área de ligação entre a alvenaria e a estrutura, pode decorrer de diversos fatores. Com o avanço da tecnologia as estruturas são mais deformáveis, mais esbeltas, menos contraventadas, pois são utilizados materiais mais leves e concretos de alta resistência, por exemplo (DALDON, 2008).

A manifestação patológica denominada de fissura na região do encunhamento em alvenarias não estruturais, ocorre devido a execução inadequada do encunhamento, as alvenarias não suportam sobrepeso de cargas verticais (CAPORRINO, 2018). A compressão dos componentes da alvenaria, provenientes da ativação de sobrecarga uniformemente distribuídas, pode causar fissuras horizontais, devido a flexo-compressão da parede pela deformação dos elementos estruturais. (THOMAZ, 1989).

As execuções das alvenarias devem seguir alguns critérios e cuidados preliminares antes e durante a execução, conforme a NBR 8545 (ABNT, 1984) o item 4.1.17 o modo indicado de travamento entre a alvenaria e a estrutura são 3 modos de execução conforme Figura 1.
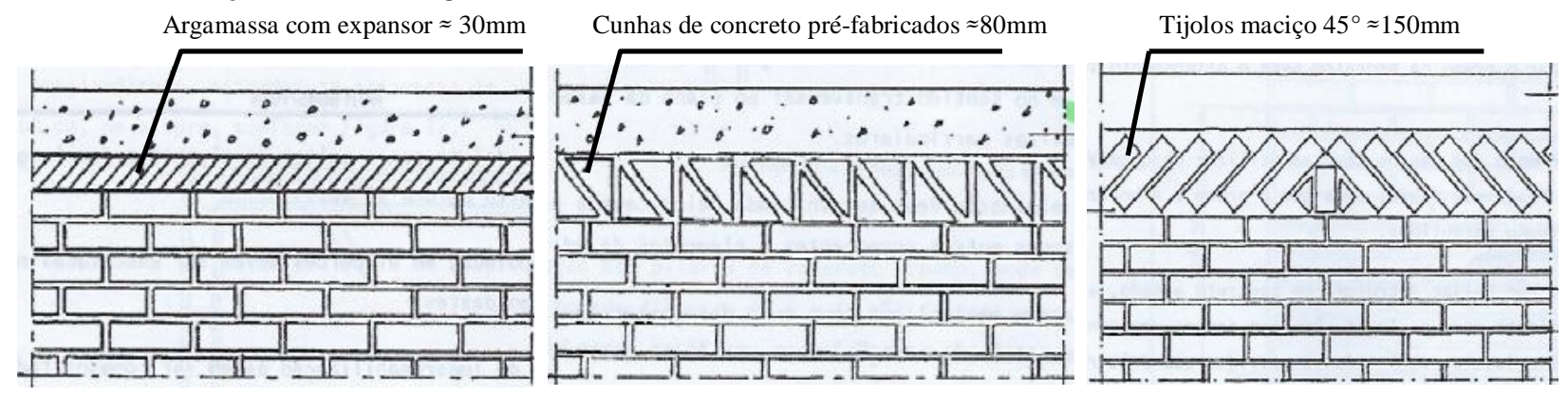

Figura 1: Travamento alvenaria/estrutura

\subsection{Os materiais para encunhamento}

- As cunhas de concreto e os tijolos cerâmicos maciços inclinados a $45^{\circ}$ são ideais para as estruturas pouco deformáveis, pois a alvenaria trabalha rigidamente com a estrutura (CAPORRINO, 2018; LORDSLEEM JUNIOR, 2004). Elas são classificadas como encunhamento pré-tensionamento (rígido), juntamente com a argamassa expansiva, com o objetivo de fixar a parede em uma estrutura indeformável (SEBBATINI, 1989).

Para o engenheiro Jonas (MEDEIROS, 2007) o encunhamento de cunhas de concreto e tijolos maciços não é mais recomendada em muitos casos, sendo tais materiais pertinentes em estruturas menos deformáveis que as desenvolvidas atualmente.

- As argamassas com aditivos expansivos, se tornam um material rígido devido ao aditivo que reduz a capacidade de retração da argamassa após a sua aplicação, aumentando a rigidez da parede de vedação, contribuindo para as manifestações patológicas do sistema (DALDON, 2008).

- A argamassa de encunhamento, é classificada como encunhamento sem pré-tensionamento ou encunhamento resiliente (DALDON, 2008), que proporciona uma união flexível, absorve os esforços de deformações da estrutura para a alvenaria (CAPORRINO, 2018; DALDON, 2008; LORDSLEEM JUNIOR, 2004)

Resiliência é a capacidade da argamassa se deformar sem que haja ruptura e retornando originalmente suas dimensões. Para tal, deve ter baixo módulo de elasticidade, alta plasticidade ou de baixo teor de cimento (argamassa podre) e aderência inicial alta, minimizando a fissuração nas alvenarias imposta pelas deformações da estrutura (SEBBATINI, 1989; DALDON, 2008; CAPORRINO, 2018). Conforme Thomaz (2007) “[...] Quanto mais flexível a estrutura e mais 
desfavoráveis as condições da parede (grande extensão ou pequena espessura), mais deformável e resilente deve ser o material de fixação $[\ldots .$.$] ".$

\subsection{Tipos de argamassa de encunhamento}

Existem várias composições de argamassas para encunhamento, supõe-se que as mais utilizadas em obras são (a) cimento, areia e aditivo expansor ou compensador de retração, argamassa de encunhamento rígido (b) cimento, areia e pasta de cal ou cola PVA, argamassa de encunhamento resiliente e (c) argamassa de encunhamento industrializadas, depende dos componentes pode ser considerada resiliente ou rígida.

\subsection{Execução do encunhamento argamassado}

Pode se considerar que os profissionais da área têm pontos de concordância e divergência. Por exemplo, a execução do encunhamento de cima para baixo é unânime pelas deformações da estrutura. Um ponto divergente é a ordem da execução, como: - a cada 4 pavimentos (MEDEIROS, 2007) (SANTOS, 2018), 2008) (LORDSLEEM JÚNIOR, 2004); - a cada 3 a 4 pavimentos (SEBBATINI, 1989); - a cada 3 pavimentos (THOMAZ, E.; FILHO,C.V.M. ; CLETO, F.R.; CARDOSO, F.F., 2009); - a cada 24 horas por pavimento (CAPORRINO, 2018) e em pavimento alternados (DALDON, 2008).

Os outros critérios de execução nem sempre são concordantes, observa-se no quadro 1 o posicionamento de diferentes profissionais e documentos técnicos.

Quadro 1: Prazos a considerar para execução do encunhamento

\begin{tabular}{|c|c|c|c|}
\hline & \multicolumn{3}{|c|}{ QUANDO EXECUTAR O ENCUNHAMENTO } \\
\hline Fonte de pesquisa & $\begin{array}{l}\text { Após o } \\
\text { término da } \\
\text { alvenaria }\end{array}$ & $\begin{array}{l}\text { Após o término da } \\
\text { estrutura }\end{array}$ & $\begin{array}{l}\text { Após a elevação da parede do } \\
\text { último pavimento a ser encunhado }\end{array}$ \\
\hline $\begin{array}{l}\text { Código de Prática de Obras n }{ }^{\circ} 1 \\
\text { (THOMAZ, E.; FILHO,C.V.M. ; CLETO, } \\
\text { F.R.; CARDOSO, F.F., 2009) }\end{array}$ & 10 dias & 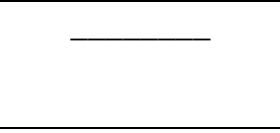 & 14 dias \\
\hline $\begin{array}{l}\text { Téchne, edição n`120 } \\
\text { (MEDEIROS, 2007) }\end{array}$ & $\begin{array}{c}3 \text { pav. } \\
\text { finalizados }\end{array}$ & 60 dias & 14 dias \\
\hline $\begin{array}{c}\text { Seminário Desempenho de Sistemas de } \\
\text { Alvenaria de Blocos Cerâmicos } \\
\text { (SANTOS, 2018) }\end{array}$ & 28 dias & $\begin{array}{c}120 \text { dias } \\
\text { concretagem }\end{array}$ & 28 dias \\
\hline $\begin{array}{c}\text { Patologia em Alvenarias } \\
\text { (CAPORRINO, 2018) }\end{array}$ & 14 dias & 60 dias & $\begin{array}{c}30 \text { dias e fixá-los após a instalação } \\
\text { do telhado }\end{array}$ \\
\hline $\begin{array}{l}\text { Trabalho de Conclusão Graduação - } \\
\text { UFRGS (DALDON, 2008). }\end{array}$ & $\begin{array}{l}2 \text { semanas de } \\
\text { intervalo }\end{array}$ & 70 dias & - \\
\hline $\begin{array}{c}\text { Assoc. Brasileira de Normas Técnicas } \\
\text { NBR } 13281 \text { (ABNT, 2005) }\end{array}$ & $\begin{array}{l}7 \text { dias (item } \\
4.1 .17 \text { pág.7) }\end{array}$ & 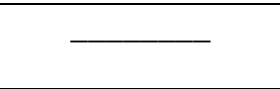 & $\begin{array}{l}7 \text { dias após o pavimento do andar } \\
\text { acima (item 4.1.18 pág.7) }\end{array}$ \\
\hline $\begin{array}{l}\text { Execução e inspeção de alvenaria } \\
\text { racionalizada } \\
\text { (LORDSLEEM JÚNIOR, 2004) }\end{array}$ & $\begin{array}{l}4 \text { pavimentos } \\
\text { livres de } \\
\text { escoramento }\end{array}$ & concluída & 30 dias \\
\hline
\end{tabular}

No quadro 2 observa-se cuidados para evitar o surgimento de manifestações patológicas. 
Quadro 2: Procedimento e cuidados para execução do encunhamento

\begin{tabular}{|c|c|c|c|}
\hline & \multicolumn{3}{|c|}{ COMO EXECUTAR O ENCUNHAMENTO } \\
\hline Fonte de pesquisa & $\begin{array}{l}\text { Espaçamento } \\
\text { alvenaria } x \\
\text { laje ao fundo } \\
\text { da viga }\end{array}$ & $\begin{array}{l}\text { Preenchimentodo } \\
\text { espaço de } \\
\text { encunhamento }\end{array}$ & $\begin{array}{l}\text { Tipo de material para o } \\
\text { encunhamento }\end{array}$ \\
\hline $\begin{array}{c}\text { Código de Prática de Obras n }{ }^{\circ} 1 \\
\text { (THOMAZ, E.; FILHO,C.V.M. ; } \\
\text { CLETO, F.R.; CARDOSO, F.F., 2009) }\end{array}$ & 1,5 a $3 \mathrm{~cm}$ & $\begin{array}{l}\text { Projetista defini se } \\
\text { preenche totalmente ou } \\
\text { dois cordões laterais. }\end{array}$ & $\begin{array}{l}\text { Não deve ser rica em cimento } \\
\text { e/ou formuladas com aditivos } \\
\text { expansores. }\end{array}$ \\
\hline $\begin{array}{c}\text { Téchne, edição }{ }^{\circ} 120 \\
\text { (MEDEIROS; THOMAZ, 2007) }\end{array}$ & $\begin{array}{l}2 \text { a } 3 \mathrm{~cm} \\
\text { (Jonas } \\
\text { Medeiros) }\end{array}$ & $\begin{array}{c}\text { - Face do bloco vazado } \\
\text { dois cordões s/vazios; } \\
\text { - Face do bloco maciço } \\
\text { toda junta. } \\
\text { (Jonas Medeiros) }\end{array}$ & $\begin{array}{c}\text { Materiais resilientes: massa } \\
\text { podre, argamassa com } \\
\text { elastômero, esferas de isopor, } \\
\text { placas de neoprene, cortiça ou } \\
\text { isopor, poliuretano expandido e } \\
\text { outros. } \\
\text { (Ercio Thomaz) }\end{array}$ \\
\hline $\begin{array}{c}\text { Seminário Desempenho de Sistemas } \\
\text { de Alvenaria de Blocos Cerâmicos } \\
\text { (SANTOS, 2018) }\end{array}$ & 2 a $3 \mathrm{~cm}$ & $\begin{array}{l}\text { Todo o vão aplicado } \\
\text { dos dois lados }\end{array}$ & $\begin{array}{l}\text { - Argamassas industrializadas; } \\
\text { - Argamassas traçadas em obra. }\end{array}$ \\
\hline $\begin{array}{l}\text { Patologia em Alvenarias } \\
\text { (CAPORRINO, 2018) }\end{array}$ & 2 a $3 \mathrm{~cm}$ & $\begin{array}{l}\text { Camada de argamassa } \\
\text { espessa e uniforme }\end{array}$ & $\begin{array}{c}\text { Argamassa resiliente, seja } \\
\text { flexível, alta plasticidade, } \\
\text { aderência e baixo módulo de } \\
\text { elasticidade }\end{array}$ \\
\hline $\begin{array}{l}\text { Trabalho de Conclusão Graduação - } \\
\text { UFRGS (DALDON, 2008). }\end{array}$ & 2 a $3 \mathrm{~cm}$ & 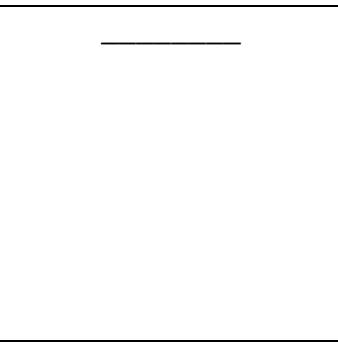 & $\begin{array}{c}\text { - Encunhamento rígido: } \\
\text { argamassa expansiva, cunhas de } \\
\text { concreto, tijolos inclinados a } 45^{\circ} ; \\
\text { - Encunhamento resiliente: } \\
\text { argamassa de baixo módulo de } \\
\text { elasticidade; } \\
\text { - Encunhamento plástico: } \\
\text { espuma de poliuretano }\end{array}$ \\
\hline $\begin{array}{c}\text { Assoc. Brasileira de Normas Técnicas } \\
\text { NBR } 13281 \text { (ABNT, 2005) }\end{array}$ & $\begin{array}{l}\approx 30 \mathrm{~mm} \\
\text { (Figura 14a } \\
\text { pág. } 8 \text { ) }\end{array}$ & $\overline{0}$ & $\begin{array}{l}\text { Argamassa com expansor } \\
\text { (Figura 14a pág.8) }\end{array}$ \\
\hline $\begin{array}{l}\text { Execução e inspeção de alvenaria } \\
\text { racionalizada } \\
\text { (LORDSLEEM JÚNIOR, 2004) }\end{array}$ & $\begin{array}{l}\text { Conforme o } \\
\text { tipo de } \\
\text { encunhameto }\end{array}$ & $\begin{array}{l}\text { Aplicar com uso de } \\
\text { bisnaga }\end{array}$ & $\begin{array}{c}\text { - Encunhamento rígido: cunhas } \\
\text { de concreto ou tijolos maciços } \\
\text { inclinados } \\
\text { - Encunhamento estrutura } \\
\text { deformável: argamassa } \\
\text { expansiva, espuma de poliuretano } \\
\text { ou argamassa rica em cal }\end{array}$ \\
\hline
\end{tabular}

\subsection{Características e propriedades da argamassa de assentamento}

Como já citado, não há norma específica para encunhamento, e assim, utiliza-se a NBR 13281 (ABNT, 2005), que classifica no item 3.2.1.3 "Argamassa para complementação da alvenaria (encunhamento): Argamassa indicada para fechamento da alvenaria de vedação, após a última fiada de componentes" NBR 13281 (ABNT, 2005), porém, sem classificação dos parâmetros pensando em específico nesse uso.

Determina-se as características e propriedades através de ensaios específicos e a classificação das argamassas conforme sua resistência à compressão Tabela 1; a densidade de massa aparente no estado endurecido; resistência à tração na flexão Tabela 2; coeficiente de capilaridade; densidade de massa no estado fresco; retenção de água e resistência potencial de aderência à tração da Norma Brasileira NBR 13281 (ABNT, 2005). 
Tabela 1: Resistência à compressão

\begin{tabular}{c|c|c}
\hline Classe & $\begin{array}{c}\text { Resistência à compressão } \\
\text { MPa }\end{array}$ & \multirow{3}{*}{ Método de ensaio } \\
\hline P1 & $\leq 2,0$ & \multirow{3}{*}{ NBR 13279 } \\
\hline P2 & 1,5 a 3,0 & \\
\hline P3 & 2,5 a 4,5 & \\
\hline P4 & 4,0 a 6,5 & \\
\hline P5 & 5,5 a 9,0 & \\
\hline P6 & $>8,00$ & \\
\hline
\end{tabular}

Tabela 2: Resistência à tração na flexão

\begin{tabular}{c|c|c}
\hline Classe & $\begin{array}{c}\text { Resistência à tração na } \\
\text { flexão MPa }\end{array}$ & \multirow{3}{*}{ Método de ensaio } \\
\hline R1 & $\leq 1,5$ & \multirow{3}{*}{ NBR 13279} \\
\hline R2 & 1,0 a 2,0 & \\
\hline R3 & 1,5 a 2,7 & \\
\hline R4 & 2,0 a 3,5 & \\
\hline R5 & 2,7 a 4,5 & \\
\hline R6 & $>3,5$ & \\
\hline
\end{tabular}

Além desses ensaios para a argamassa de encunhamento é importante o módulo de elasticidade, a redução é favorável a argamassa de encunhamento, sendo compatível com sua função, evitando deformações excessivas que possam danificar a alvenaria de vedação, o revestimento, comprometendo a aderência a estrutura, consequentemente a durabilidade e a estanqueidade.

\section{MATERIAIS E MÉTODOS}

A metodologia deste trabalho, através de pesquisa pelo método quantitativo, com intuito de comparar os parâmetros de desempenho entre a argamassa industrializada e argamassa areia x cimento x aditivo expansor, através de levantamento de dados obtidos por ficha técnica de produtos e ensaios laboratoriais executados conforme as normas técnicas relacionadas a cada fase, como preparo da mistura, moldagem, cura e ensaios. Catalogaram-se dados de características físicas de 07 empresas que comercializam argamassa industrializada e 03 empresas de aditivo expansor, e características mecânicas de 02 argamassas industrializadas e 02 argamassas convencionais adicionado aditivo expansor de marcas diferentes.

\subsection{Características técnicas}

Foram obtidas as características técnicas com as empresas do desempenho dos produtos, apontados no quadro 3, através das fichas técnicas, apresentam a classificação conforme a NBR13281 (ABNT, 2005).

Quadro 3: Desempenho do produto da argamassa industrializada

\begin{tabular}{|c|c|c|c|}
\hline Empresa - data emissão & Resistência à compressão & Densidade estado endurecido & Resistência tração na flexão \\
\hline ARG $1-27 / 09 / 18^{* *}$ & --------- & --------- & -------- \\
\hline ARG 2 - Não tem & P3*-2,5 a 3,0 MPa & M5* - 1600 a $2000 \mathrm{~kg} / \mathrm{m}^{3}$ & $\mathrm{R} 2-2,7$ a $4,5 \mathrm{MPa}$ \\
\hline ARG $3-06 / 05 / 13$ & $\mathrm{P} 3 *-2,5$ a $4,5 \mathrm{MPa}$ & $\mathrm{M}^{*}-1600$ a $2000 \mathrm{~kg} / \mathrm{m}^{3}$ & $\mathrm{R} 2 *-1,0$ a $2,0 \mathrm{MPa}$ \\
\hline ARG 4 - Não tem & $\mathrm{P} 4 *-4,0$ a $6,5 \mathrm{MPa}$ & M5* - 1600 a $2000 \mathrm{~kg} / \mathrm{m}^{3}$ & \\
\hline ARG $5-07 / 07 / 16$ & P3* - 2,5 a 4,5 MPa & M5* -1600 a $2000 \mathrm{~kg} / \mathrm{m}^{3}$ & $\mathrm{R} 2 *-1,0$ a $2,0 \mathrm{MPa}$ \\
\hline ARG 6 - Não tem & $\mathrm{P} 3 *-2,5$ a $4,5 \mathrm{MPa}$ & M4* -1400 a $1800 \mathrm{~kg} / \mathrm{m}^{3}$ & --------- \\
\hline ARG $7-10 / 03 / 14$ & 28 dias $50 \mathrm{MPa}$ & --------- & -------- \\
\hline \multicolumn{4}{|c|}{$\begin{array}{l}\text { *Classificados pela NBR13281/05. } \\
\text { **Somente o Módulo de elasticidade dinâmico - 1,842 MPa, conforme ensaio do laboratório. } \\
\text { OBS- Dados retirados das fichas técnicas dos produtos das empresas estudas. }\end{array}$} \\
\hline
\end{tabular}

Outros dados pertinentes ao estudo, contendo instruções de preparo do produto, aplicação, rendimento, tempo de utilização, classificação e outras informações do produto, sendo tais dados apresentados no quadro 04 . Pode-se 
constatar que dentre as empresas não há um consenso entre as maneiras de execução do encunhamento. Não somente o modo de preparo e a forma de aplicação.

Quadro 4: Informações e recomendações das fichas técnicas da argamassa industrializada.

\begin{tabular}{|c|c|c|c|}
\hline $\begin{array}{c}\text { Empresa - } \\
\text { data }\end{array}$ & Composiçao & Preparo & Aplicação \\
\hline $\begin{array}{l}\text { ARG } 1- \\
27 / 09 / 18\end{array}$ & $\begin{array}{l}\text { - cimento Portland; } \\
\text { - cal hidratada CH-II; } \\
\text { - blend de agregados minerais } \\
\text { calcários e quartzoso; } \\
\text { - filer mineral; } \\
\text { - aditivos químicos } \\
\text { compensadores de retração. }\end{array}$ & $\begin{array}{l}\text { 4,4 a } 4,8 \text { litros água p/saco de } \\
\text { 25kg. Mistura obrigatoriamente } \\
\text { em betoneira ou misturador de } \\
\text { argamassa, nunca manualmente. }\end{array}$ & $\begin{array}{l}\text { Espessura ideal de } 2 \text { a } 3 \mathrm{~cm} \text {, injetar } \\
\text { argamassa até preencher } \\
\text { completamente o espaço existente, } \\
\text { compactando totalmente o material } \\
\text { no interior vazio. }\end{array}$ \\
\hline $\begin{array}{l}\text { ARG 2 - } \\
\text { Não tem }\end{array}$ & $\begin{array}{l}\text { - cimento Portland; } \\
\text { - cal hidratada; } \\
\text { - areia quartzosa classificada; } \\
\text { - aditivos químicos não } \\
\text { tóxicos. }\end{array}$ & $\begin{array}{l}7,0 \text { e } 7,5 \text { litros de água p/saco de } \\
\text { 40kg. Homogeneizar a mistura } \\
\text { evitando a formação de grumos }\end{array}$ & $\begin{array}{l}\text { Espessura de } 10 \mathrm{~mm} \text {, pois é a que se } \\
\text { consegue o melhor desempenho do } \\
\text { produto em relação à resistência e à } \\
\text { compressão, molhar os blocos } \\
\text { cerâmicos. }\end{array}$ \\
\hline $\begin{array}{l}\text { ARG } 3- \\
06 / 05 / 13\end{array}$ & $\begin{array}{l}\text { - cimento Portland; } \\
\text { - agregados minerais com } \\
\text { granulometria controlada; } \\
\text { - aditivos químicos. }\end{array}$ & $\begin{array}{l}12,8 \% \text { a } 13,2 \% \text { de água a } \\
\text { temperatura } 18^{\circ} \mathrm{C} \text { e } 25^{\circ} \mathrm{C} \text {. } \\
\text { Mistura manual ou mecânica } \\
\text { argamassadeira, o tempo varia } \\
\text { conforme o tipo de equipamento } \\
\text { e quantidade de saco deve ser } \\
\text { controlado pelo operador. }\end{array}$ & $\begin{array}{l}\text { Espalhar a argamassa sobre o bloco } \\
\text { pressionando-o para que haja uma } \\
\text { boa aderência argamassa e bloco, } \\
\text { retirando o excesso com a colher. } \\
\text { Cuidados temperatura ambiente } \\
\text { superior a } 30^{\circ} \mathrm{C} \text {, bloco superior } \\
28^{\circ} \mathrm{C} \text { e umidade relativa do ar } \\
\text { inferior a } 40 \% \text {. }\end{array}$ \\
\hline $\begin{array}{l}\text { ARG } 4- \\
\text { Não tem }\end{array}$ & $\begin{array}{l}\text { - cimento cinza; } \\
\text { - cal hidratada; } \\
\text { - areias selecionadas; } \\
\text { - aditivos químicos. }\end{array}$ & $\begin{array}{l}6,5 \text { a } 7,5 \text { litros de água p/saco } \\
50 \mathrm{~kg} \text { e misturar em betoneira } \\
\text { por no mínimo de } 3 \text { minutos, ou } \\
\text { em argamassadeira, ou ainda } \\
\text { manualmente até a perfeita } \\
\text { homogeneização. }\end{array}$ & $\begin{array}{l}\text { Preencher a folga do encunhamento } \\
\text { por um lado da parede, com colher } \\
\text { de pedreiro e compactando-a com } \\
\text { um soquete de madeira, completar } \\
\text { pelo outro lado após } 12 \text { horas. } \\
\text { Executar o encunhamento em } \\
\text { grupos de } 3 \text { pavimentos e iniciar de } \\
\text { cima para baixo, com intervalo de } \\
24 \text { horas entre eles. }\end{array}$ \\
\hline $\begin{array}{l}\text { ARG 5- } \\
07 / 07 / 16\end{array}$ & $\begin{array}{l}\text { - agregados minerais; } \\
\text { - cimento Portland; } \\
\text { Aditivos químicos não } \\
\text { tóxicos. }\end{array}$ & $\begin{array}{l}\text { Entre } 12 \% \text { a } 15 \% \text { de água em } \\
\text { betoneira ou misturador } \\
\text { contínuo. }\end{array}$ & $\begin{array}{l}\text { Espalhar a argamassa sobre o bloco } \\
\text { pressionando-o para que haja uma } \\
\text { boa aderência argamassa e bloco, } \\
\text { retirando o excesso com a colher, } \\
\text { junta acabada de no mínimo } 1,0 \mathrm{~cm} \\
\text { de espessura, umedecer levemente } \\
\text { os blocos. }\end{array}$ \\
\hline $\begin{array}{l}\text { ARG 6-- } \\
\text { Não tem }\end{array}$ & $\begin{array}{l}\text { - cimento Portland; } \\
\text { - cal Geo; } \\
\text { - areias selecionadas; } \\
\text { - aditivos químicos. }\end{array}$ & $\begin{array}{l}5,5 \text { a } 6,5 \mathrm{~L} \text { de água p/saco de } 40 \\
\mathrm{~kg} \text {. Misturar em argamassadeira } \\
\text { por um tempo mínimo de } 5 \\
\text { minutos ou até ficar homogênea. }\end{array}$ & $\begin{array}{l}\text { Disposto na norma técnica ABNT } \\
\text { NBR7200* e NBR15961-2** }\end{array}$ \\
\hline $\begin{array}{l}\text { ARG } 7- \\
10 / 03 / 14\end{array}$ & Não possui & $\begin{array}{l}2,375 \text { litros água p/saco de } \\
25 \mathrm{~kg} \text {. Misturar em } \\
\text { argamassadeira por um tempo } \\
\text { mínimo de } 5 \text { minutos, ou em } \\
\text { betoneira, ou ainda } \\
\text { manualmente até a perfeita } \\
\text { homogeneização }\end{array}$ & $\begin{array}{l}\text { Preencher a folga do encunhamento } \\
\text { por um lado da parede, com colher } \\
\text { de pedreiro e compactando-a com } \\
\text { um soquete de madeira, completar } \\
\text { pelo outro lado após } 12 \text { horas }\end{array}$ \\
\hline
\end{tabular}

NBR7200 Execução de revestimento de paredes e tetos de argamassas inorgânicas - Procedimento;

**NBR15961-2 Alvenaria estrutural - Blocos de concreto;

OBS- Dados retirados das fichas técnicas dos produtos das empresas estudas. 
O aditivo expansor também é plastificante, é um produto em pó com propriedades expansivas e plastificante, de modo a compensar a retração plástica causada pela hidratação do cimento, para ser adicionado à pasta de cimento e argamassa e concretos, no quadro 5, 03 empresas que comercializam o aditivo descriminado sua forma de aplicação e modo de preparo.

Quadro 5: Forma de aplicação e modo de preparo do aditivo expansor

\begin{tabular}{|c|c|c|c|}
\hline $\begin{array}{l}\text { Empresa - } \\
\text { data }\end{array}$ & Utilização & Preparo & Aplicação \\
\hline $\begin{array}{l}\text { AD } 1- \\
\text { Não tem }\end{array}$ & $\begin{array}{l}\text { - encunhamento em geral; } \\
\text { - preenchimento em geral, } \\
\text { com argamassa tipo dry-pack } \\
\text { (consistência seca) }\end{array}$ & $\begin{array}{l}\text { Traço 1:6 areia média limpa, } \\
\text { água até atingir uma } \\
\text { consistência seca para } \\
\text { aplicação. }\end{array}$ & $\begin{array}{l}\text { Encunhamento uma fresta de } 3 \mathrm{~cm} \text {, } \\
\text { mistura a seco, preferencialmente } \\
\text { betoneira e argamassadeira por } \\
\text { aproximadamente } 3 \mathrm{~min} \text {. depois } \\
\text { adicione a água }\end{array}$ \\
\hline $\begin{array}{l}\text { AD } 2- \\
01 / 06 / 13\end{array}$ & $\begin{array}{l}\text {-argamassa de encunhamento; } \\
\text { - pasta e argamassa de } \\
\text { enchimento de espaços vazios; } \\
\text {-injeção de pasta de cimento } \\
\text { em fundações, cavidades e } \\
\text { fissuras em rochas. }\end{array}$ & $\begin{array}{l}\text { Encunhamento -traço } 1: 3 \text { de } \\
\text { areia média lavada, } 1 \% \text { sobre o } \\
\text { peso do cimento }\end{array}$ & $\begin{array}{l}\text { Adicionado ao cimento seco, a } \\
\text { mistura preferencialmente com } \\
\text { agitação mecânica (betoneira) } 40 \% \\
\text { a } 45 \% \text { de água em relação ao } \\
\text { cimento, consistência plástica/seca }\end{array}$ \\
\hline $\begin{array}{l}\text { AD 3- } \\
\text { Abril/15 }\end{array}$ & $\begin{array}{l}\text { - para diminuir a retração } \\
\text { plástica ; } \\
\text { - pasta para bainhas de } \\
\text { protensão; } \\
\text { - concretos, argamassas e } \\
\text { pasta com menor fator } \\
\text { água/cimento }\end{array}$ & $\begin{array}{l}0,5 \% \text { a } 1 \% \text { sobre a massa do } \\
\text { cimento }\end{array}$ & $\begin{array}{l}\text { Nas áreas preenchidas deve estar } \\
\text { seco, limpo, isento de óleos e } \\
\text { desmoldantes, pó e partículas } \\
\text { soltas. Processo expansivo em } 20 \\
\text { minutos após mistura. }\end{array}$ \\
\hline
\end{tabular}

OBS- Dados retirados das fichas técnicas dos produtos das empresas estudas.

\subsection{Material e moldagem do corpo de prova}

A confecção e ensaios das argamassas foram realizados no itt Performance, localizado na Universidade do Vale do Rio dos Sinos - UNISINOS. Para a confecção foram encontradas no mercado do Rio Grande do Sul apenas 2 argamassas industrializadas nos quais foram ensaiadas e escolhido 2 marcas de aditivos expansor mais utilizadas, totalizando 4 traços com quantidade de água e preparo da mistura diferentes, utilizando o equipamento de pesagem a balança eletrônica de resolução $1 \mathrm{~g}$ marca Level, e para mistura a argamassadeira de eixo vertical de marca Fortest. As argamassas são descritas a seguir:

- $\quad$ Argamassa AD1 de traço areia média x cimento Portland CPIV-32, com aditivo expansor, conforme a embalagem o modo de preparo e traço da mistura de 1:6 mais 1\% do peso do cimento de aditivo, sendo a massa específica de $357 \mathrm{~g}$ de cimento, $2142 \mathrm{~g}$ de areia média, 3,6g de aditivo e adicionado $222 \mathrm{ml}$ de água, introduzido na argamassadeira a mistura seca por 3 minutos, para ficar uma mistura homogênea, adicionado a água aos poucos e continua a mistura até completar 6 minutos. Argamassa com consistência seca para a moldagem do molde1 (figura 2a).

- $\quad$ Argamassa AD2 de traço areia média x cimento Portland CPIV-32, com aditivo expansor, na embalagem não possui informações para o modo de preparo e traço da mistura, portanto foi utilizado a proporção da mistura conforme a ficha técnica (quadro 4) de 1:3 mais $1 \%$ do peso do cimento de aditivo, sendo a massa específica de $625 \mathrm{~g}$ de cimento, $1875 \mathrm{~g}$ de areia média, 6,3g de aditivo e adicionado 40 a $45 \%$ de água, modo de preparo igual a argamassa anterior, adicionado $281 \mathrm{ml}(45 \%)$ de água. Argamassa com consistência plástica/seca para a modelagem do molde 2 (figura 2 b).

- $\quad$ A argamassa industrializada ARG1, conforme informações da embalagem, sua composição é uma mistura seca à base de cal hidratada CH-II, areia industrial classificada à base de rocha calcária e quartzo, cimento Portland CPII-Z32 e aditivos químico especiais compensadores de retração, adicionar água de 3,3 a 4,10 litros por $25 \mathrm{~kg}$ (divergente do quadro 4), foi separada a massa específica seca de $2500 \mathrm{~g}$ e a massa de água $410 \mathrm{~g}$ (o limite máximo de água), sendo utilizada 330g de água, a mistura foi realizada conforme as recomendações NBR16541 (ABNT,2016) item 5.2.1. A argamassa ficou homogênea e sem grumos com consistência plástica (pastosa), para a moldagem molde 3 (figura 2c). 
- $\quad$ A argamassa industrializada ARG2, conforme informações da embalagem, sua composição é uma mistura seca de cimento Portland, areia natural, cal hidratada e aditivos especiais não tóxicos, adicionar água de 4,0 a 4,50 litros por $25 \mathrm{~kg}$ (divergente do quadro 4), foi separada a massa específica seca de $2500 \mathrm{~g}$ e a massa de água $450 \mathrm{~g}$ (o limite máximo de água), sendo utilizada 338g de água, a mistura foi realizada conforme as recomendações NBR16541 (ABNT,2016) 16 item 5.2.1. A argamassa ficou homogênea e sem grumos com consistência plástica/seca, para a moldagem do molde 4 (figura 2d).

Moldaram-se amostras com dimensões de 4 X 4 X $16 \mathrm{~cm}$, conforme figura 4, de 3 corpos de prova para cada traço de argamassa, totalizando 12 corpos de provas conforme a NBR13279 (ABNT, 2005). Foram moldados em única camada, desmoldados após 48h, e permaneceram em ambiente do laboratório, para simular o mais próximo possível do ambiente da obra. (NBR 16541, 2016; NBR 13279, 2005).
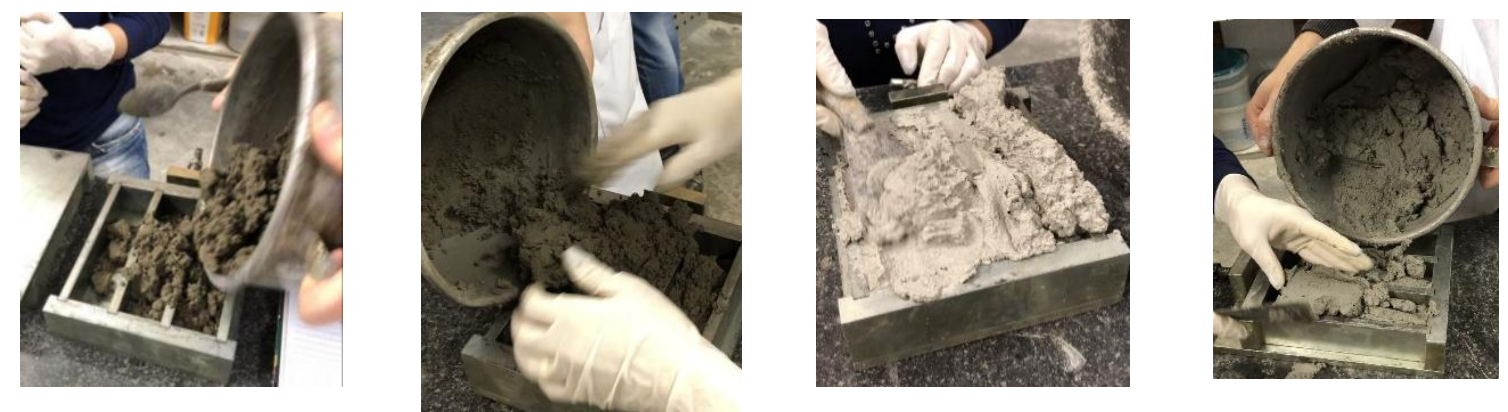

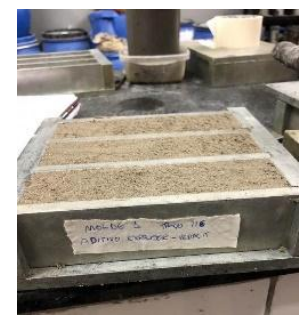

(a)

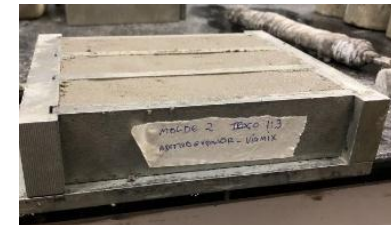

(b)

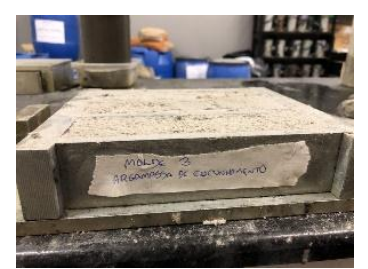

(c)

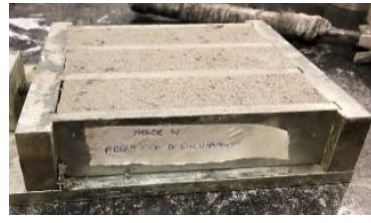

(d)

Figura 2 - Consistência da argamassa e moldagem dos corpos de prova

\subsection{Ensaios realizados}

Os ensaios foram realizados aos 28 dias de acordo com as recomendações das normas NBR 13279 (ABNT, 2005) e NBR 15630 (ABNT, 2008), os corpos de prova foram pesados e medidos determinando a densidade $\boldsymbol{\rho}$ da massa no estado endurecido em $\mathrm{kg} / \mathrm{m}^{3}$, o primeiro ensaio realizado foi de módulo de elasticidade dinâmico através da propagação de onda ultra-sônica, realizado conforme a NBR15630 (ABNT, 2008), utilizando o aparelho portátil marca Pundit lab modelo proceq conforme figura 3. O método de transmissão foi o direto.

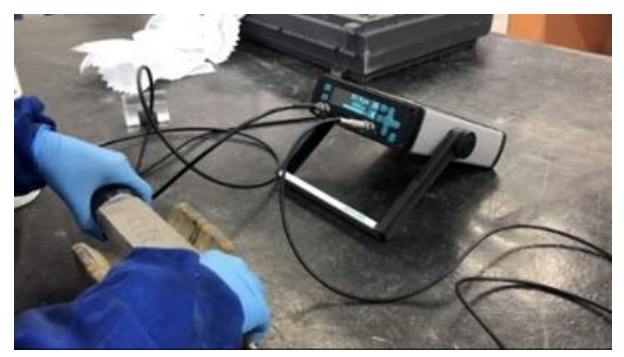

Figura 3 - Ensaio de módulo de elasticidade, aparelho ultrassom

Determinou-se a velocidade de propagação $\mathcal{V}$ de ondas ultra-sônicas (VOU), leva para percorre o corpo do de prova, obtida utilizando a equação (A).

Equação A

$\mathcal{V}=\frac{\mathbf{L}}{\mathbf{t}} \quad \begin{aligned} \mathrm{L} & =\text { Comprimento do corpo de prova }(\mathrm{mm}) \\ \mathrm{t} & =\text { Tempo registrado micro segundos }(\mu \mathrm{S})\end{aligned}$ 
Após a determinação da velocidade, calculou-se o módulo de elasticidade dinâmico $\mathbf{E}_{\mathbf{d}}$ da argamassa em MPa, através da equação adaptada (B) e aplicado o coeficiente de Poisson 0,2 NBR 15630 (ABNT, 2008), é a razão entre a deformação transversal e longitudinal de uma carga de compressão axial aplicada no corpo de prova (HEINECK, 2012).

Equação B

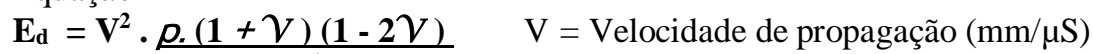

$$
\begin{aligned}
& (\mathbf{1}-\boldsymbol{V}) \quad \rho=\text { Densidade de massa }\left(\mathrm{Kg} / \mathrm{m}^{3}\right) \\
& \mathcal{V}=\text { coeficiente de Poisson } 0,2
\end{aligned}
$$

O segundo ensaio determina a resistência a tração na flexão, conforme NBR 13279:05, foi utilizado a prensa marca Instron modelo Emic 23-300, com a unidade de carga $50 \mathrm{~N} / \mathrm{s}$ até a ruptura. O ensaio realizado com aplicação de carga central do corpo de prova apoiado em 2 pontos conforme figura 4a e na figura 4 b a ruptura à flexão NBR 13279 (ABNT, 2005) e NBR 13276 (ABNT, 2016).

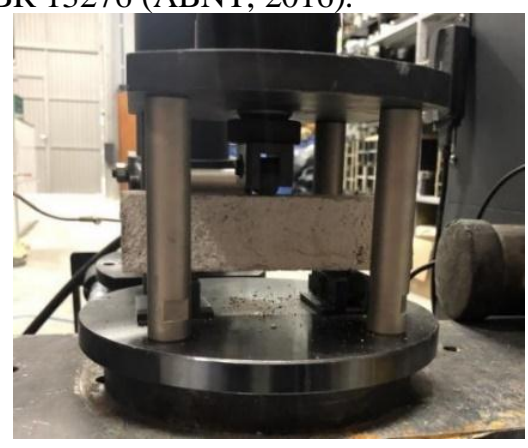

(a)

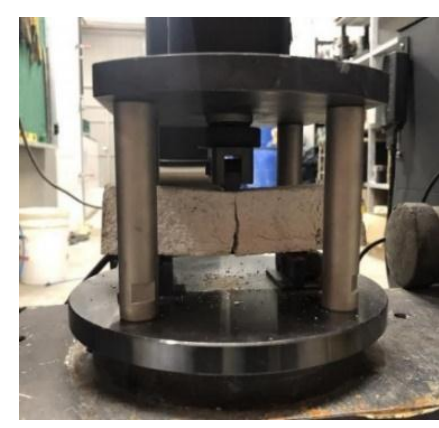

(b)

Figura 4 - Ensaio de resistência à tração na Flexão

Conforme os dados coletados nos ensaios aplicaram-se a equação $(C)$ e obteve-se o resultado da resistência à tração na flexão.

Equação C

$$
\begin{aligned}
& \mathbf{R}_{\boldsymbol{f}}=\mathbf{1 , 5} \cdot \underline{\mathbf{F}_{f} \cdot \mathbf{L}} \mathrm{R}_{f}=\text { Resistência à tração na flexão }(\mathrm{MPa}) \\
& \mathbf{4 0}^{\mathbf{3}} \quad \mathrm{F}_{f}=\text { Carga aplicada no centro do prima }(\mathrm{N}) \\
& \mathrm{L}=\text { Distância entre os pontos de apoio }(\mathrm{mm})
\end{aligned}
$$

O terceiro ensaio realizado determina a resistência à compressão das argamassas, conforme a NBR 13279 (ABNT,2005) utilizou-se os dois pedaços do corpo de prova do ensaio de flexão, na mesma prensa usada no ensaio anterior, mas sendo a unidade de carga $500 \mathrm{~N} / \mathrm{s}$ até a ruptura, conforme figuras $5 \mathrm{a}$ e $5 \mathrm{~b}$.

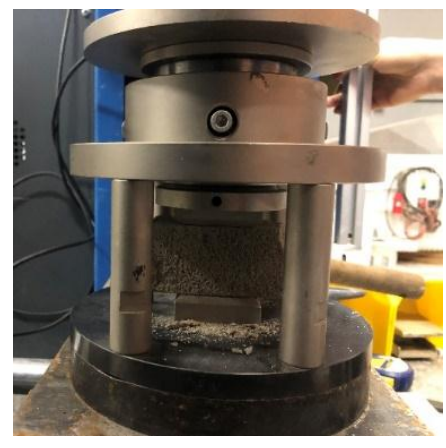

(a)

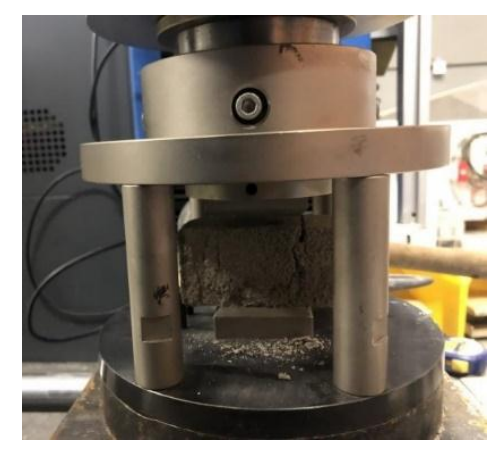

(b)

Figura 5 - Ensaio de resistência à compressão

Conforme os dados coletados nos ensaios aplicaram-se a equação (D) e obteve-se o resultado da resistência à compressão. 
Equação D
$\mathbf{R}_{c}=\frac{\mathbf{F}_{c}}{1600}$
$\mathrm{R}_{c}=$ Resistência à compressão $(\mathrm{MPa})$
$\mathrm{F}_{c}=$ Carga máxima aplicada $(\mathrm{N})$
$\mathrm{A}=$ Área da seção $\left(\mathrm{mm}^{2}\right) 40 \mathrm{mmx} 40 \mathrm{~mm}=1600 \mathrm{~mm}^{2}$

\section{ANÁLISE DOS RESULTADOS}

Através da análise quantitativa dos resultados referente aos 3 corpos de prova de cada traço, calculou-se a resistência média e o módulo de elasticidade médio, obtidos através dos ensaios realizados. No quadro 6 constam os resultados médios obtidos das variáveis já citadas.

Quadro 6: Resultados médios dos ensaios das argamassa de encunhamento

\begin{tabular}{c|c|c|c|c|c|c}
\hline Mistura & $\begin{array}{c}\text { Densidade de } \\
\text { massa } \\
\left(\mathbf{k g} / \mathbf{m}^{3}\right)\end{array}$ & $\begin{array}{c}\text { Tempo de } \\
\text { propagação da } \\
\text { OU }(\boldsymbol{\mu s})\end{array}$ & $\begin{array}{c}\text { VOU } \\
(\mathbf{m} / \mathbf{s})\end{array}$ & $\begin{array}{c}\text { Módulo de } \\
\text { elasticidade } \\
(\mathbf{G P a})\end{array}$ & $\begin{array}{c}\text { Resistência à } \\
\text { tração na } \\
\text { flexão }(\mathbf{M P a})\end{array}$ & $\begin{array}{c}\text { Resistência à } \\
\text { compressão } \\
(\mathbf{M P a})\end{array}$ \\
\hline $\mathbf{1 : 6 ~ A D ~ 1 ~}$ & 1823 & 55,9 & 2.865 & 13,57 & 2,26 & 8,90 \\
\hline $\mathbf{1 : 3 ~ A D ~ 2 ~}$ & 1996 & 45,0 & 3.582 & 23,41 & 4,20 & $22,53^{*}$ \\
\hline ARG 1 & 1573 & 105 & 1.529 & 3,32 & 0,38 & 0,62 \\
\hline ARG 2 & 1731 & 55,8 & 2.893 & 13,05 & 2,53 & $10,02^{*}$ \\
\hline
\end{tabular}

Os resultados são também apresentados através do gráfico 1.

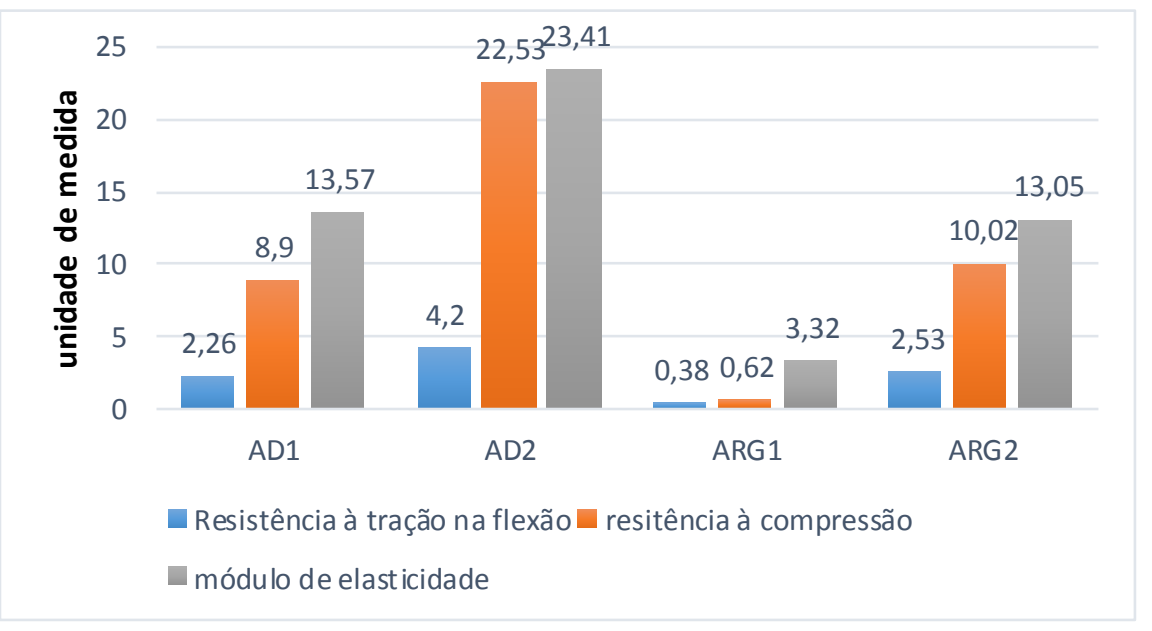

Gráfico 1 : Resultados laboratoriais das argamassas aos 28 dias

Calculou-se os seus desvios e foram descartados os desvios absolutos máximo superiores a 0,3MPa na flexão e 0,5MPa na compressão conforme itens 6.4 e 6.5, da NBR 13279 (ABNT,2005), aos 28 dias de idade das argamassas produzidas com areia: cimento: aditivo expansor e argamassas de encunhamento industrializadas. Os ensaios de resistência à compressão das amostras AD2 e ARG2 não são válidos, pois não atingiram a média de no mínimo de 4 corpos de prova, após o cálculo dos desvios máximos permitidos pelo item 6.5 da NBR 13279 (ABNT,2005), devendo ser refeitos os ensaios.

A argamassa AD1 resultado de resistência média à compressão aos 28 dias de 8,9 MPa classificada como P6 NBR 13281 (ABNT,2005) considerada encunhamento rígido (DALDON, 2008, THOMAZ, 2000). A argamassa ARG1 resultado de resistência média à compressão aos 28 dias de $0,62 \mathrm{MPa}$, classificada como P1 (NBR 13281, 2005) considerada como encunhamento resiliente (DALDON, 2008, THOMAZ, 2000). Estes resultados de resistência à compressão estão relacionados ao traço, pode-se concluir que o traço de areia, cimento e aditivo, são superiores ao traço da argamassa industrializada que possui cal CH II (CAPORRINO, 2018). 
Os ensaios de resistência à tração na flexão aos 28 dias das argamassas AD1 com 2,26 MPa e ARG2 com 2,53 MPa classificadas como R3, a AD2 com 4,20 MPa classificada como R6 e a ARG1 com 0,38 MPa classificada com R1 NBR 13281 (ABNT, 2005). O ensaio de módulo de elasticidade está diretamente relacionado ao tempo de propagação da onda ultra- sônica, quanto maior o tempo, a velocidade da onda é menor, assim aumentando o módulo de elasticidade (SILVA; CAMPITELI, 2008).

Percebeu-se que a ARG1 teve o maior desempenho em relação ao módulo de elasticidade e a resistências mecânicas aos 28 dias de cura, por ter na sua composição areia industrial (rocha calcária e quartzo) essa areia possui maior teor de material pulverulento e com menor fator de água/cimento pode favorecer o aumento do módulo de elasticidade (SILVA; CAMPITELI, 2008) e o aditivo de incorporador de ar e plastificante aumento a trabalhabilidade, maior índice de vazios, maior porosidade, em conformidade menor densidade e menor resistência mecânica (HEINECK, 2012). Para argamassa de encunhamento o módulo de elasticidade é muito importante absorvendo as deformações da estrutura, mas não muito baixo, podendo causar manifestações patológicas nos revestimentos, através de deformações excessivas (SILVA; CAMPITELI, 2008).

\section{CONSIDERAÇÕES GERAIS}

Com levantamentos realizados através de acervos técnicos de vários profissionais da área, demonstrou uma vasta variação de informações de execução e materiais no que tange ao encunhamento, o que pode ser decorrente da ausência de normas técnicas que regulamentem teu material.

Através do programa experimental realizado, não pode-se atribuir o melhor desempenho a nenhuma argamassa, mas pode-se concluir que entre as argamassas ensaiadas, apenas uma das argamassas industrializada a ARG 1 obteve o desempenho satisfatório para ser utilizada na função de encunhamento, com baixa resistência mecânica à flexão e à compressão, influenciando no resultado do módulo de elasticidade, classificando como argamassa resiliente, portanto uma argamassa mais deformável e não rígida.

A necessidade de ser estabelecido uma norma brasileira com parâmetros e formas de execução classificando o sistema de estrutura, com controles sobre o agregado ou diversos agregados na composição da argamassa, em relação ao traço, com aditivos ou não, volume de água e o tempo de mistura, reduzindo a variabilidade das proporções dos materiais.

\section{REFERÊNCIAS}

ASSOCIAÇÃO BRASILEIRA DE NORMAS TÉCNICAS. NBR 13276: Argamassa para assentamento e revestimento de paredes e tetos - Determinação do índice de consistência. Rio de Janeiro, 2016.

ASSOCIAÇÃO BRASILEIRA DE NORMAS TÉCNICAS. NBR 13279: Argamassa para assentamento e revestimento de paredes e tetos- Determinação da resistência à tração na flexão e à compressão. Rio de Janeiro, 2005.

ASSOCIAÇÃO BRASILEIRA DE NORMAS TÉCNICAS. NBR 13281: Argamassa para assentamento e revestimento de paredes e tetos - Requisitos. Rio de Janeiro, 2005.

ASSOCIAÇÃO BRASILEIRA DE NORMAS TÉCNICAS. NBR 15630: Argamassa para assentamento e revestimento de paredes e tetos - Determinação do módulo de elasticidades dinâmico através da propagação de onda ultra-sônica. Rio de Janeiro, 2008.

ASSOCIAÇÃO BRASILEIRA DE NORMAS TÉCNICAS. NBR 16541: Argamassa para assentamento e revestimento de paredes e tetos - Preparo da mistura para a relaização de ensaios. Rio de Janeiro, 2016.

ASSOCIAÇÃO BRASILEIRA DE NORMAS TÉCNICAS. NBR 8545: Execução de Alvenaria sem Função Estrutural de Tijolos e Blocos Cerâmicos. Rio de Janeiro, 1984.

CAPORRINO, C. Patologias em alvenarias. São Paulo: Oficina de Textos, 2018. 
DALDON, M. Fatores que podem estar contribuindo para o aparecimento de manisfetações patológicas na zona de encunhamento de paredes em obras de Porto Alegre. 2008. 80f . Mamografia, conclusão de curso de graduação Engenharia Civil, UFRGS. Porto Alegre, RS, Brasil, 2008.

HEINECK, S. Desempenho de argamassas de revestimento com incorporação da fração miúda da britagem de concreto. 2012. 134f. Pós Graduação Engenharia Civil - Universidade do Vale do Rio dos Sinos - UNISINOS. São Leopoldo, RS, Brasil, 2012.

LORDSLEEM JÚNIOR, A. Execução e inspeção de alvenaria racionalizada. São Paulo: Rosa Editora 2004.

MEDEIROS, J. Última fiada - Planejamentoda ligação da alvenaria à estrutura exige atenção à sequência de aplicação das sobrecargas na edificação Téchne - edição 120, março,2007 Disponível em : http://techne17.pini.com.br/engenharia-civil/120/artigo287425-1.aspx

SANTOS, M. D. Medidas de Projeto e execução para Assegurar o Desempenho das Vedações na Interface Estrutura Concreto X Alvenaria de Blocos Cerâmicos. Seminário Desempenho de Sitemas de Alvenaria de Blocos Cerâmicos. São Paulo, SP, Brasil, 2008

SEBBATINI, F. 1989. Desenvolvimentode métodos, processos e sistemas construtivos - formação e aplicação de uma metodologia. Tese (doutorado) Escola Politécnica, Universidade de São Paulo, São Paulo, SP, Brsil, 1989.

SILVA, N. G.; CAMPITELI, V. C. Módulo de Elasticidade Dinâmico de Argamassa de Revestimento $2^{\circ}$ Encontro de Engenharia e Tecnologia dos Campos Gerais. Ponta Grossa, Paraná, Brasil, 2006.

THOMAZ, E. Trincas em Edificios, causas prevenção e recuperação. São Paulo: Pini, 1989.

THOMAZ, E. No encunhamento de alvenaria de tijolo baiano, comparativamente ao tradicional encunhamentocom tijolos de barro cozido, qual a eficiência dos sistemas alternativos (aperto com argamassa) e quais os procedimentos corretos para execução desse tipo.. Revista PINI, 12/12/200. Disponível em: http://piniweb17.pini.com.br/construcao/noticias/no-encunhamento-de-alvenarias-de-tijolo-baiano-comparativamenteao-tradicional-84053-1.aspx

THOMAZ, E. Última fiada - Planejamento da ligação à estrutura exige atenção à sequência de aplicaçã das sobrecargas na edificação, Téchne - edição 120, março 2007. Disponível em: http://techne17.pini.com.br/engenhariacivil/120/artigo287425-1.aspx

THOMAZ, E.; FILHO, C. V. M.; ClETO, F. R.; CARDOSO, F. F. Código de Prárticas n 1 - Alvenaria de Vedação em Blocos Cerâmicos. São Paulo: IPT - Instituto de Pesquisa Tecnológica do Estado de São Paulo, 2009. 